\title{
New Approaches to Simulation-Based Science Instruction to Enhance Reasoning and Communication Skills in Lebanese Elementary Education
}

\author{
Layal Temsah $^{1}$, Nehme Safa ${ }^{2}$ \\ ${ }^{1}$ Ph.D. Candidate, Education Management, Saint Joseph University of Beirut., P.O Box 17-5208- \\ Lebanon \\ ${ }^{2}$ Associate Professor, Educational Research Laboratory, Faculty of Educational Sciences, Saint \\ Joseph University of Beirut, P.O Box 17-5208-Lebanon
}

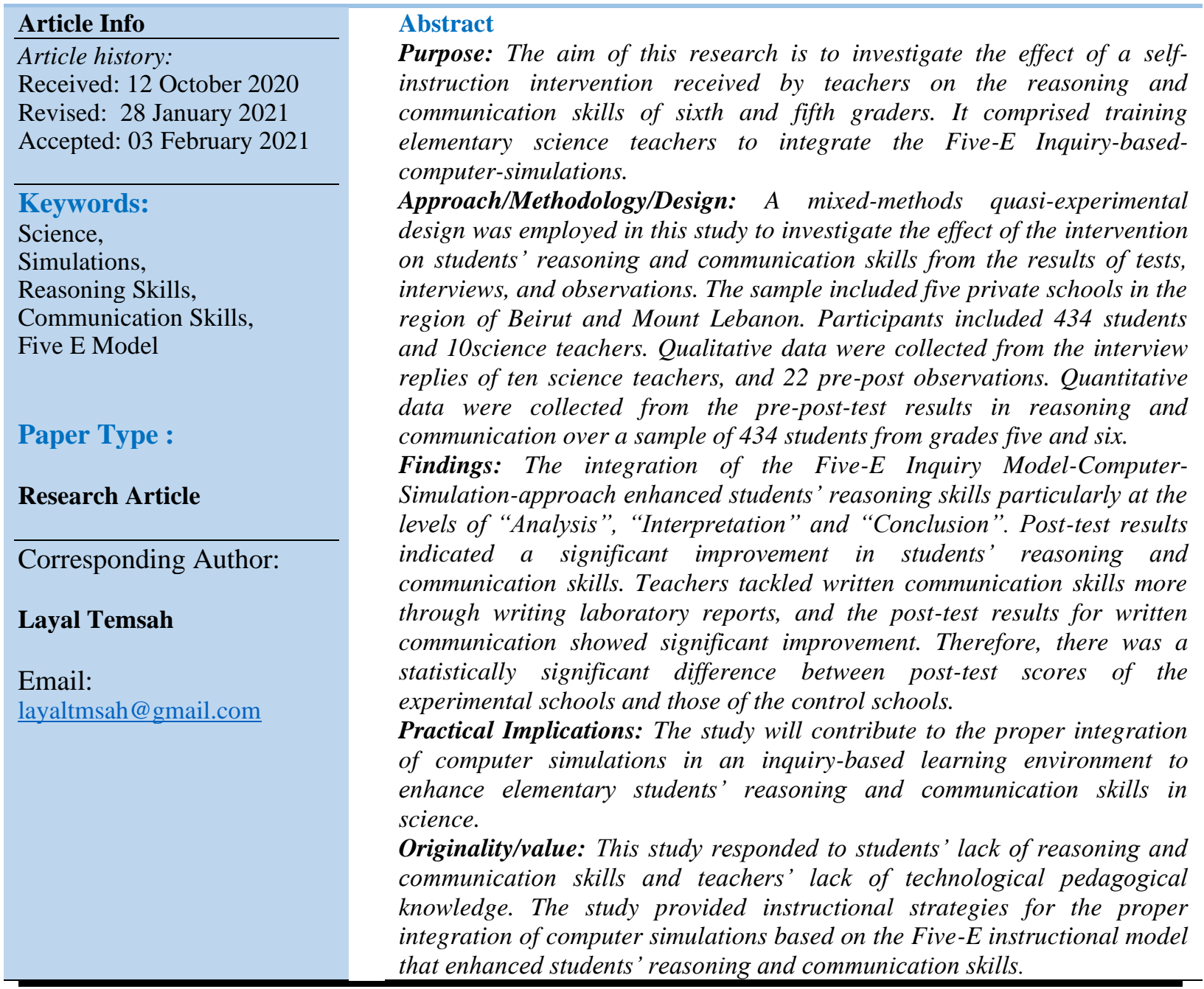

\section{Introduction}

With the outbreak of the COVID-19 Pandemic in 2019, accompanied by the worldwide lockdown, ICT integration in education became inevitable. Therefore, research has 
emphasized the need for providing proper education which increases competence and training for information technology (IT) (Fauzi \& Sastra Khusuma, 2020). ICT literacy has emerged as a core and mandatory skill to be attained by learners from all grade levels internationally, added to teachers' need for the effective integration of interactive technology to address the requirements of completing school curricula (Dong, Cao, \& $\mathrm{Li}, 2020$ ). In response to this pandemic and its consequences on the education sector, many reports and research studies in education have tackled the role of simulations as interactive learning environments in achieving the required learning that entails higher order thinking skills (Kriz, 2020). Those skills represent the core of any science curricula (Williamson \& Anderson, 2019).Findings from empirical research have demonstrated that integrating computer-simulations based on the Five-E instructional model enhanced learning by providing opportunities for learners to develop the skills of identifying problems, analyzing, organizing, evaluating (which fall under the sub-skills of reasoning), and communicating information (Lee et al., 2002).

As for the case of Lebanon, former studies have reported worrying findings regarding the status quo of science education. For instance, the results of TIMSS 2003, 2007, 2011 and 2015, in Lebanon scored lower than the international mean score for grade-eight in the competencies of knowledge, reasoning, and application; the latter two of which fell under the umbrella of higher levels of thinking besides communication as part of science process skills (Bou Jaoude, 2007; Dagher and Bou Jaoude, 2011; OECD, 2013; Foy et al., 2015, Lee et al., 2002). The Lebanese National Centre for Educational Research and Development (NCERD) has specified reasoning, communication, and inquiry skills as core competencies to be acquired by elementary students (NCERD, 1999). However, no Lebanese research has highlighted the proper instructional practices which could be implemented to tackle elementary students' reasoning and communication skills in science using simulations. Despite the established evidence from previous research on the role of the Five-E-computer Simulation-Model in developing reasoning and communication skills (Dickes et al., 2019; Greenspan, 2016), research studying the effect of using simulations based on the Five-E instructional model on elementary students' reasoning and communication skills in Lebanon has not been conducted yet (Yehya, 2018). Therefore, the question that raises itself is: Where does Lebanon stand regarding Five-E computer simulation-interventions which aim to improve elementary students' reasoning and communication skills in science?

In Lebanese schools, students are struggling with the reasoning and communication skills as witnessed in TIMSS results, and there is a need for a drastic solution for this issue as those skills are mandated by the Lebanese science curriculum (Zeitoun \& Hajo, 2015). Further, research has shown the positive effect of simulation based on Five E instructional model on enhancing cognitive skills (Lye et al., 2014). Unfortunately, the use of simulation-based FiveE instructional model has not been looked into in the elementary science education in Lebanon. Therefore, this study investigates the effect of integrating simulations-based Five-E instructional model on enhancing elementary students' reasoning and communication skills in elementary science. 


\section{Literature Review}

This study can be viewed through the lens of social constructivism, the technological pedagogical content Knowledge (TPACK) theory, Bloom's taxonomy, and the theory of information processing.

\section{Social Constructivism}

This theory stems from the works of John Dewey whose conception of thinking was associated with scientific inquiry. In his report called Science in general education, he described the elements of an instructional model for teachers to promote reflective thinking among students. His model was further developed by Atkin and Karplus into the BSCS (Biological Science Curriculum Study) Five-E-Inquiry model (Forman \& Pufall, 1988; Maida, 2011; Miranda, 2011). It comprised five phases: (1) Engagement, (2) Exploration, (3) Explanation, (4) Elaboration, and (5) Evaluation (Bybee et al., 2006; Bybee, 2014).

\section{TPACK}

As for the TPACK theory, Mishra and Koelher (2006) developed a framework called the technological, pedagogical content knowledge (TPACK) (Nordin et al., 2013; Chai et al., 2010; Erdogan \& Sahin, 2010). This model requires teachers to attain sufficient knowledge of technology, pedagogy, content, and the intersection of these to integrate ICT effectively in their classrooms. Technology knowledge (TK) involves the awareness of technology tools to be used in instruction. Pedagogical knowledge (PK) refers to the knowledge of the proper instructional strategies which encompass practices to deliver teaching, to assess students' learning needs, and to deliver the required content with adequate performance and techniques (Nordin et al., 2013; Erdogan \& Sahin, 2010). The content knowledge (CK) refers to knowledge of the subject in which the teachers specialize. The intersections between the three produce the pedagogical content knowledge (PCK), technological content knowledge (TCK), and technological pedagogical knowledge (TPK) (Erdogan \& Sahin, 2010). PCK pertains to using effective teaching strategies in the instruction of the prescribed content (Nordin et al., 2013; Erdogan \& Sahin, 201). TCK refers to teachers' realization of instances in which technology can be effectively integrated into their subject-content (Nordin et al., 2013), whereas TPK requires the understanding of using technology with convenient teaching strategies (Nordin et al., 2013). At the core of the intersection between these domains lies the TPACK model, which necessitates the knowledge of how to integrate technology in pedagogically rigorous methods to teach the subject-matter content.

\section{Bloom's Taxonomy}

Bloom, Englehart, Furst, Hill, and Krathwohl as cited in Halawi, Pires, and McCarthy (2009) have classified learning into three domains of behavior, one of which being the cognitive domain. Later, Anderson and Krathwohl as cited in Krathwohl (2002) revised the taxonomy and produced a refined corrected version of the cognitive process. It has included the revised levels written as verbs and gerunds instead of nouns to specify the cognitive processes which 
thinkers encounter. These verbs are: to remember, to understand, to apply, to analyze, to evaluate, and to create. The first four verbs correspond to higher levels of thinking which have been defined by the Lebanese curriculum as reasoning skills (Halawi et al., 2009; Hughes, 2014; Krathwohl, 2002; NCERD, 1999).

\section{Information Processing Theory}

Atkinson and Shiffrin $(1968,1971)$ as cited in Tangen \& Borders (2017) clarified the Information Processing Theory (IPT)by relating the neurological activities for collecting and retrieving information to computer functioning. They described three memory stores: sensory memory, short-term memory (STM), and long-term memory. If the given material is attended to, it will enter short-term memory also known as working memory (WM). However, when there is too much information for the WM to process, this leads to STM overload. The instructional design should reduce memory overload and stimulate meaningful learning to enhance learners' critical thinking. Atkinson and Shiffrin $(1968,1971)$ as cited in Tangen \& Borders (2017) and Schunk (2016) have highlighted several strategies that conserve information in the STM or WM:

1. Maintenance rehearsal or repeating information over and over.

2. Elaborative rehearsal, which implies relating the new material to previously known information.

3. Organization, which means chunking information into significant units.

In this study, upper elementary students can achieve better reasoning and communication skills by reducing memory overload through integrating simulations which correspond to chunking the information, relating it to prior knowledge, and allowing students to rehearse the information givenby manipulating variables (Schunk, 2016). Therefore, reducing memory overload requires active learning strategies which associate additional information to previously acquired one, and which promote group work and thinking time among students. Examples of these strategies include the KWLH strategy (What I know, what I want to learn, what I learned, How I learned), Think-pair-share, and Cueing students' responses (BouJaoude, 2018).

\section{Simulation-based Five-E Instructional Model}

As for simulations, they were defined as:

A model of a real system and conducting experiments with this model to understand the behavior of the system and/or evaluate various strategies for the operation of the system. Thus the model must be designed in such a way that the model behavior mimics the response behavior of the real system to events that take place over time. (Duran, 2018, p. 7) 
Simulations present models for observing and manipulating target systems to draw inferences from such models. As for the Five-E instructional model, and as previously mentioned, it was developed by Dewey and later elaborated on by Atkin and Karplus into a model of Guided Discovery. The latter model was modified by Karplus and Thier into the Learning Cycle. It included three phases: (1) exploration where teachers begin with an initial experience with the phenomenon, (2) invention where students are introduced to new terms related to the concept of the study, and (3) discovery where students apply concepts and use the terms in new situations (Bybee et al., 2006). Later on, in the mid-1980s, the Science Curriculum Improvement Study (SCIS model) SCIS model was further developed into an instructional model to teach science for the elementary classes called the BSCS (Biological Science Curriculum Study) Five-E-Inquiry model. It comprised five phases, three of which were equivalent to the three phases of the SCIS learning cycle to explore the topic of interest (Exploration), the invention of the relevant explanations (Invention), and discovery through testing and elaboration (Discovery) on the studied topic. The five phases of BSCS encompassed (1) Engagement, (2) Exploration, (3) Explanation, (4) Elaboration, and (5) Evaluation (Bybee et al., 2006; Bybee, 2014). In the engagement phase, a teacher introduces the topic in an interesting introduction and relates it to students' prior knowledge. In the exploration phase, students explore the topic in an activity. In the explanation phase, students explain what they learned from a topic. Finally, in the elaboration, students' understanding is further expanded through new experiences, whereas the evaluation phase requires students to assess their understanding of a concept (Bybee et al., 2006; Greenspan, 2016).

\section{Inquiry Learning}

As for inquiry learning, it has been defined as one which actively engages students in posing questions, formulating hypotheses, investigating, testing their hypotheses, evaluating and communicating their findings (Pedaste et al., 2015). Empirical research has defined simulations as most convenient for inquiry-based activities because of their interactive nature, their data presentation feature through tables or graphs, and their ability to offer multiple representations of the same or varied concepts at once. Therefore, simulations based on the Five-E Inquiry Model were defined as ones which allow: "genuine interactivity in terms of active learner contribution and engagement”, (Hennessy et al., 2006, p.702; Lye et al., 2014, p.122). Simulations based on the Five-E instructional model have been defined as ones which were customized to fit the elementary cycle and to tailor for the requirements of discovery learning by reducing cognitive load and affording for deeper learning where students become engaged in knowledge acquisition. Therefore, simulations based on Five-E Engage students by eliciting their prior understanding through videos, allow students to Explore the studied concept by discovering the simulation variables, they also permit students to deepen their understanding or Elaborate by performing an exercise embedded in the simulation, and at last they direct students to evaluate their understanding by performing further manipulations in the simulation (Lye et al., 2014). 


\section{Recent Research in Adopting Simulations and the Five-E Instructional Model}

In their study, Lye et al. (2014) examined the designing, customizing, and the implementation of simulation in an elementary class based on the Constructivist BSCS Five-E instructional model. They adopted a case study approach to reflect how the open source energy simulation was modified to fit the elementary cycle whereby the case represented the phases of design, customization, and implementation of the simulation in an elementary school in Singapore. Qualitative data collected through field notes, focus group interviews with students, and Google form submissions showed that students perceived their learning experience as positive and found the simulation features as useful and engaging in self-directed learning. A survey on 27 students quantitatively supported these findings (Lye et al., 2014).Therefore, in this study it was evident that students manifested a support and likelihood to implement the simulation-based Five-E instructional model in science. However, the complementarity between such integration and performing hands-on laboratory practices demanded further research in this regard.

In light of the need for further analysis of simulation-use as compared to concrete learning, Unlu and Dokme (2014) explored seventh graders' opinions regarding the integration of computer simulations concurrently with laboratory activities in science classes. Findings suggested that computer simulations and laboratory activities be used as mutually paired in science courses. Therefore, the integration of simulations was established as complementary to laboratory practices (Unlu \& Dokme, 2014). Consequently, computer-simulations could be used as pre-laboratory training sessions to introduce learners to the new concepts and experimental setups virtually before conducting hands-on experiments. However, this complementarity highlighted the need for effective instructional strategies to cater for the proper use of simulations in an inquiry-based learning environment.

Dalgarno et al. (2014) indicated the importance of incorporating proper instructional strategies when using simulations. This study has provided evidence that pure discovery learning using computer-based simulations was of limited significance and strategies which minimize complexity and give guidance to learners have become essential. The results demonstrated that systematic exploration of computer simulations using the predict-observeexplain approach produced learning benefits while unsystematic exploration did not. Therefore, designers of computer simulations were recommended to add guidance to students during their exploration of the simulation and make it more systematic by varying one parameter at a time. Subsequently, this study shed light on the importance of developing instructional strategies that improve the learning outcomes of students when integrating computer simulations in an inquiry-based learning environment (Dalgarno et al., 2014).Therefore, further research needed to highlight the impact of integrating simulations on students' skills, provided that it is associated with inquiry-based learning environments and adequate instructional practices. 
In this regard, a meta-analysis by Smetana and Bell (2012) aimed to explore the effect of using computer simulations on science teaching and learning through a comprehensive review of 61 empirical research studies. The overall findings reported that computer simulations could be as or even more effective than physical hands-on instructional practices in enhancing science process skills which included communication in addition to reasoning and problem solving. The collective findings have reported the importance of integrating simulations to engage students in inquiry-based authentic scientific explorations, and to use them for better conceptual understanding of scientific content prior to conducting hands-on experiments. Other benefits included flexibility, safety, and efficiency. Accordingly, their study highlighted the beneficial role of simulations in tackling students' reasoning and communication skills in science, and relating them to laboratory practices (Smetana \& Bell, 2012). However, the impact of such integration needed to be addressed in the Lebanese context and in light of using the Five-E instructional model. Therefore, a recent empirical Lebanese study by Harbali (2018) has been reported. The purpose of this study was to study the effect of integrating inquiry-based virtual laboratories (computer simulations) on the engagement and achievement of eleven graders in inquiry skills. A quasi-experimental design was used whereby the experimental group received inquiry-based virtual laboratory lessons while the control group was taught using the Five-E inquiry model solely. Findings indicated that students who received inquiry-based virtual labs showed better achievement in genetic engineering than those who were taught using only the Five-E instructional model. Therefore, the Five-E inquiry model was found to be more effective in enhancing students' learning when integrated with computer simulations (Harbali, 2018).

These studies combined made a foundation for the research question guiding this study:

How does implementing the simulation-based Five-E instructional model affect students' reasoning and communication skills in learning science?

Two null hypotheses are proposed:

- No significant difference exists in the mean scores of elementary students taught using simulation-based Five-E instructional model and those taught conventionally on the reasoning pre-and post-test.

- No significant difference exists in the mean scores of elementary students taught using simulation-based Five-E instructional model and those taught conventionally on the written communication pre-and post-test.

\section{Methodology and Procedures}

\section{Research Design}

This study adopted the mixed-methods quasi-experimental design over a sample of 434 students, and 10 participating teachers in five schools labelled as follows: A, B, C, and D for 
treatment schools while school E was control. The intervention comprised a teacher training session introduced to the participating teachers, it included a Self-Instruction approach whereby teachers attended a power point presentation associated with a handbook for explanations and training exercises. The training involved teachers in completing several tasks which trained them to practice the integration of computer simulations with the Five-EInquiry Model. It trained teachers to implement a number of active learning strategies including the KWLH, Think-Pair-Share, and Cueing student responses (BouJaoude, 2018).

\section{Research Population and Sample}

The population consisted of all teachers and students in private schools that use English as an instruction medium of science in Lebanon The sample encompassed five private elementary schools which agreed to participate in the study and with a significant ICT infrastructure. The sample was purposively selected based on the researcher's previous knowledge of the population and based on the objectives of the study, and it included all grade-six and five sections in each one of the participating schools, and their science teachers. The total number of participating students was 434, and the total number of participating teachers was 10 . These schools were well reputed for their good achievement in science; they had Internet, active boards, computer laboratories, and used a foreign science curriculum.

Only Grades 5 and 6 were chosen for this study due to their conformity to literature findings which defined these grade levels as most beneficial for integrating ICT (Becker and Park, 2011). Moreover, the elementary cycle was chosen since simulation use through the Five-E instructional model was designed for elementary-grade students (Bybee, 2009; Shope \& McComas, 2015; Hsu, et al., 2016; Singh, Singh, Kumari, \& Kumar, 2011; Tsai, 2017).

\section{Research Instruments}

The study used a researcher-made semi-structured interviews to science teachers before and after the intervention to understand their perspectives regarding simulation integration. The qualitative facet also has employed semi-structured observations of teachers' classroom practices before, during, and after the intervention to go deeper in the qualitative depiction of the schools' culture, types of teacher-student and student-student interaction, language used and social structure in each school (Creswell, 2014). Furthermore, the quantitative quasiexperimental phase has involved using pre-tests before the implementation of the intervention to both experimental and control schools to determine students' level in reasoning and written communication skills. After the intervention, post-tests were conducted to each of the experimental and control schools to know if there was a difference in reasoning skills (graded out of 15) and written communication skills (graded out of 5) especially among the experimental group who received the intervention training. The findings obtained from these data collection tools were used for triangulation.

\section{Research Procedure}


Before commencing the study, the researcher informally met the principals of the five schools (experimental and control) to explain the purpose of the study and its significance and to gain their approval to participate. The researcher also met the participating teachers informally and explained to them the research procedure and what they should expect throughout the process. Everything concerning the study was well explained to the participating schools to assure their required consent to participate and their cooperation when conducting the study. The conduct of the study commenced upon receiving the formal approval. The researcher also enhanced the validity of the research pre-and post-tests by conducting a pilot study. In the pilot study the researcher introduced the pre-test and post-test to a sample of 20 students to check for its content validity, and afterwards the researcher made the corresponding modifications.

\section{A. Pre-test}

A researcher-made pre-test was conducted to fifth and sixth graders of both the experimental and control schools. The purpose of the pre-test was to track the level of students in reasoning and written communication skills prior to conducting the intervention and to confirm that they were achieving at the same level in these two skills. Students' scores were recorded for statistical analysis.

\section{B. Pre-observation}

The researcher conducted semi-structured pre-observations before introducing the intervention in each one of the experimental and control schools. The purpose of the preobservations was to track teachers' classroom practices when integrating simulations and students' engagement in response to this integration. The researcher also planned to compare data collected from pre-observations with those emerging from post-observations to track changes in teachers' instructional practices after receiving the intervention, and to explore changes in students' interaction with the teacher as a result of the intervention. Data collected from these observations were recorded as frequencies and percentages for statistical data treatment.

\section{Pre-interviews}

The researcher conducted semi-structured interviews with the science teachers of each of both experimental and control schools. The purpose of the pre-interview was to report teachers' perception of integrating simulations and their understanding of the best practices involved in this regard. The researcher also aimed to reflect any possible changes in teachers' perceptions after receiving the intervention thus highlighting its effect on teachers' views and understanding of the integration of simulations.

\section{Intervention Phase}

The researcher introduced a training session to the participating teachers in the four experimental schools. The training involved a Power Point presentation including an audio recording which instructed the teachers to do a number of tasks associated with videos and a 
handbook. The training acquainted teachers with a number of instructional strategies to implement when integrating simulations based on the Five-E instructional model.

\section{Post-test}

After three weeks from the time of the training, the researcher gave a post-test to students in both experimental and control schools. The post-test was conducted to see if there has been a difference on students' science reasoning and written communication scores through the integration of computer simulations based on the Five-E instructional model. Students' scores were recorded and used for statistical analysis using the SPSS program. The researcher calculated measures of the independent and dependent samples t-test.

\section{E. Post-observation}

Two weeks after the training session, the researcher conducted semi-structured observations in the four experimental schools. The purpose of the post-observations was to track changes in teachers' instructional practices and in students' interactions as a result of the intervention.

\section{F. Post-interviews}

One week after the intervention, the researcher conducted semi-structured interviews with the same teachers of the experimental group who received the intervention. The objective of the post-interview was to probe teachers' attitudes towards the integration of the ComputerSimulation-Five-E instructional model.

\section{Operational Definitions of the Variables}

In this study, reasoning was operationally defined as students' ability to (Hardy et al., 2010; Wu et al., 2016; NCERD, 1999; OECD, 2009; OECD, 2013):

1- pick up information from a given text, diagram, graph, table, or scheme;

2- differentiate between causes and effects;

3 - pose a question based on a given situation;

4- suggest a prediction/hypothesis that answers the problem;

5- identify dependent and independent variables;

6- analyze the data that shows the relationship between the variables;

7- interpret results of an experiment; and derive conclusions.

As for written communication, it was operationally defined as students' ability to:

1- write a meaningful text of 3-4 sentences using clear and appropriate scientific terms describing a scientific process or phenomenon;

2- draw a table or graph that shows the relationship between the studied variables (NCERD, 1999). 


\section{Results and Discussion}

\section{Results from Tests}

The first part of this section presents the descriptive information of both the experimental and control schools' achievement on the pre-and post-tests. The second part presents the inferential data with the corresponding analysis and interpretation to reveal the differences between the experimental and control schools' performance in reasoning and communication before and after the intervention.

Table 1.1 indicates the mean scores of each of the experimental and control schools at the pre-test phase in reasoning. The 319 students of the experimental group who have taken the pre-test in reasoning $(\mathrm{M}=8.1, \mathrm{SD}=3.4)$, and compared to the 115 students in the control group who took the same pre-test in reasoning $(\mathrm{M}=8.6, \mathrm{SD}=3.1)$, showed no significant difference in achievement at this level, $\mathrm{t}(432)=1.37, \mathrm{p}=0.169$. Therefore, there was no significant difference between the experimental and control schools in reasoning skills before introducing the intervention. Therefore, any observed differences between the two groups after conducting the intervention should be due to the intervention itself.

As for written communication skills, the results are also presented in Table 1.1. The 319 students in the experimental group who have done the pre-test in written communication $(\mathrm{M}=1.5, \mathrm{SD}=1.5)$, and compared to the 115 students in the control group who sat for the same pre-test in written communication $(\mathrm{M}=1.5, \mathrm{SD}=2.1)$, showed no significant difference in achievement at this level, $\mathrm{t}(432)=0.63, \mathrm{p}=0.527$. Therefore, there was no significant difference between the experimental and control schools in written communication skills before conducting the intervention. Accordingly, the possible changes in achievement at the level of written communication skills after the training should be due to the intervention.

Table 1: The Independent Samples T-Test

\begin{tabular}{lllllll}
\hline Test & Group & $\mathrm{M}$ & $\mathrm{SD}$ & $\mathrm{t}(432)$ & $\mathrm{P}$ & $\begin{array}{c}\text { Hedge's } \\
\mathrm{g}\end{array}$ \\
\hline Reasoning Pre- & & & & & & \\
test & Experimental & 8.1 & 3.4 & 1.37 & 0.169 & \\
& Control & 8.6 & 3.1 & & & \\
Written & & & & & & \\
$\begin{array}{l}\text { Communication } \\
\text { Pre-test }\end{array}$ & Experimental & 1.5 & 1.5 & 0.63 & 0.527 & \\
& Control & 1.5 & 2.1 & & & \\
Reasoning & Experimental & 8.9 & 2.9 & 7.52 & 0 & 0.99 \\
Post-test & Control & 5.5 & 4.6 & & & \\
Written & & & & & & \\
Communication & & & & & & \\
Post-test & Experimental & 2.4 & 1 & 6.83 & 0 & 0.92 \\
& Control & 1.3 & 1.6 & & & \\
\hline
\end{tabular}

Legend: $M=$ Mean, $S D=$ Standard deviation, $t$ (degrees of freedom $)=$ the $t$ statistic, $p=p$ value Source: Authors 
After the intervention was introduced, post-tests in reasoning and written communication skills were given to each of the experimental and control schools, and the results were statistically presented in Table 1.1. As shown in Table 1.1, the 319 students in the experimental group who have done the post-test in reasoning after the intervention $(\mathrm{M}=8.9$, $\mathrm{SD}=2.9)$ compared to the 115 students in the control group who took the same test $(\mathrm{M}=5.5$, $\mathrm{SD}=4.6$ ), achieved significantly better scores in reasoning, $\mathrm{t}(432)=7.52, \mathrm{p}=.00$. Consequently, the first null hypothesis was rejected. Therefore, students in the experimental group outperformed their counterparts in the control group at the level reasoning skills after their teachers had received the intervention training, with an effect size Hedge's $g=0.99$.

As for written communication, the 319 students in the experimental group who have done the post-test in this skill after the intervention $(\mathrm{M}=2.4, \mathrm{SD}=1)$ compared to the 115 students in the control group who did the same post-test $(\mathrm{M}=1.3, \mathrm{SD}=1.6)$, achieved significantly better scoresin written communication $\mathrm{t}(432)=6.83, \mathrm{p}=.00$. Accordingly, the second null hypothesis was rejected. Therefore, the intervention had a significant effect in enhancing students' written communication skills in science. As indicated in these results, students in the experimental group had outperformed their peers in the control group at the level of written communication post-test, with an effect size Hedge's g=0.92.

Concerning the effect size measure, and since this study comprised different sample sizes for each of the experimental and control groups, Hedge's g measure was calculated and found to be equal to 0.99 for reasoning and Hedge's $g=0.92$ for written communication. Thus the two measures of effect size were large implying that the intervention was very effective, which in turn gave more power to the study and quantified its effect numerically (Cohen et al., 2018). Those results matched what the literature has reported about the positive effects of integrating computer simulations in enhancing science process skills including reasoning and communication (Smetana \& Bell, 2012).

Table 1.2 presents the results of the dependent samples t-test to show the differences in performance within each of the experimental and control groups on the pre and post-tests. Based on Table 1.2, the results from the pre-test $(\mathrm{M}=8.1, \mathrm{SD}=3.4)$ and post-test in reasoning for the experimental group $(\mathrm{M}=8.9, \mathrm{SD}=2.9)$ demonstrated that the introduction of the simulation-based Five-E instructional model training to teachers resulted in the improvement of the experimental students' reasoning skills. Therefore, there was a significant increase in the experimental group's scores on reasoning skills after the intervention compared to their scores before the intervention as indicated by $\mathrm{t}(318)=15$, and $\mathrm{p}=0.00$.

Table 1.2 also presents the difference in the scores of the experimental group on written communication skills between the pre-test and the post-test. Based on this table, there was a significant increase in the scores of the experimental group in written communication skills in the post-test $(M=2.4, S D=1)$ compared to their scores in the pre-test $(M=1.5, S D=1.5), t(318)$ $=15.3$, and $\mathrm{p}=0.00$. Consequently, the intervention was successful in enhancing the experimental group's reasoning and written communication skills in science. 
As for the control school, and based on Table 1.2, there was a significant decrease in students' scores in reasoning in the post-test phase $(\mathrm{M}=5.5, \mathrm{SD}=4.6)$ compared to their scores in the pre-test $(\mathrm{M}=8.6, \mathrm{SD}=3.1), \mathrm{t}(114)=6.3$, and $\mathrm{p}=0.00$. In addition, there were no significant differences in the scores of the control group in written communication skills in the post-test $(\mathrm{M}=1.3, \mathrm{SD}=1.6)$ compared to the pre-test scores $(\mathrm{M}=1.4, \mathrm{SD}=2.1), \mathrm{t}(114)=0.7$, and $\mathrm{p}=0.51$. These results are in line with what the empirical research study by Lye et al. (2012) has reported about the positive effects of integrating simulations which are customized with the Five-E instructional model on students' engagement and self-directed learning in science.

Table 2: The Dependent Samples T-Test

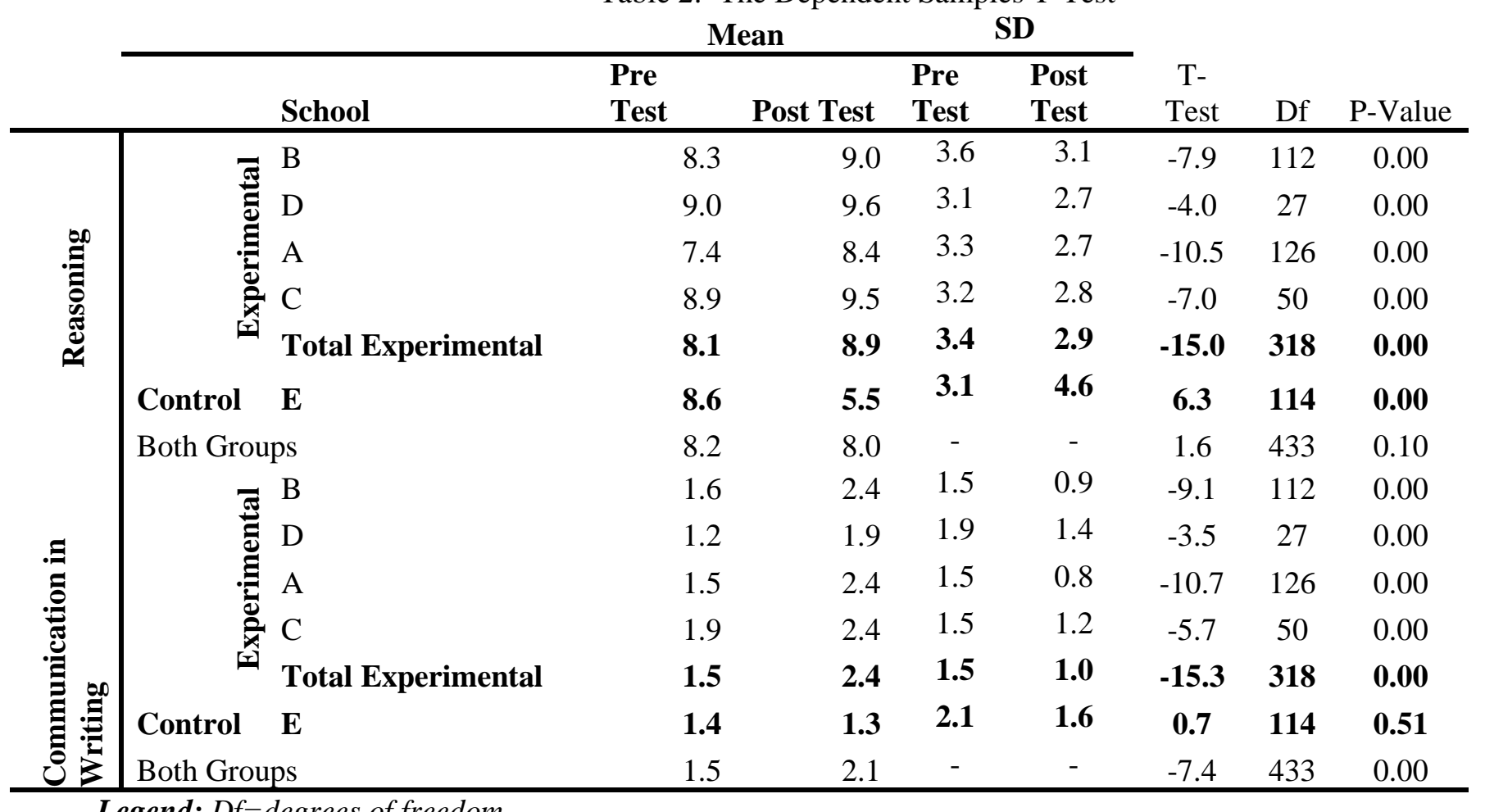

Legend: $D f=$ degrees of freedom

Source: Authors 


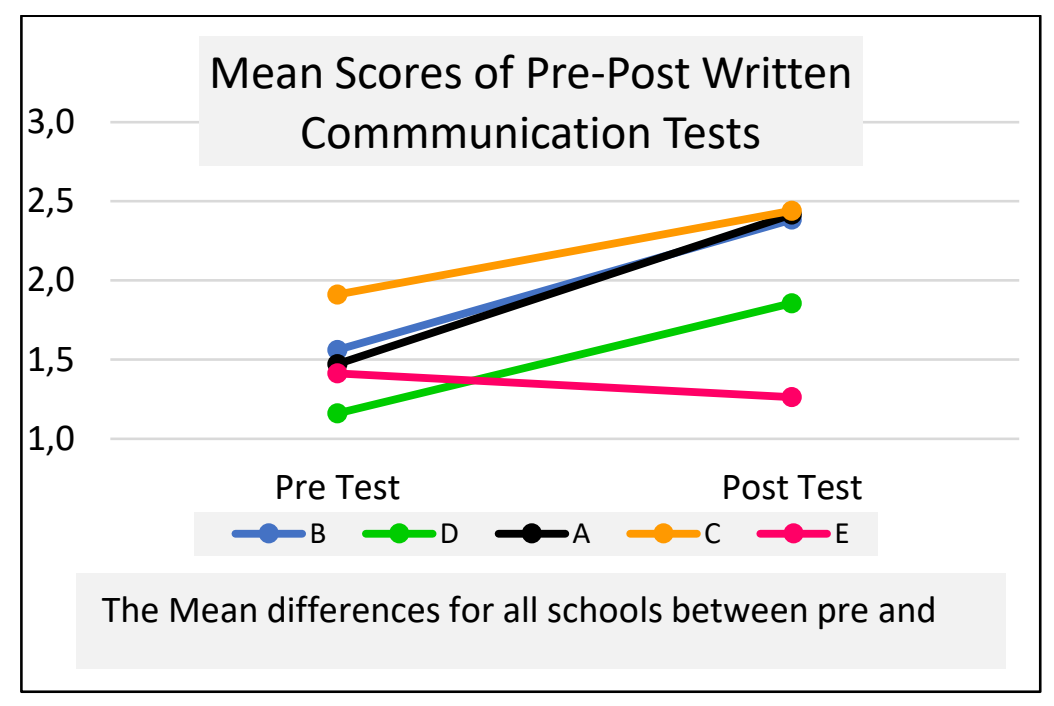

Figure 1: Mean Scores of Pre-Post Written Communication Tests

\section{Results from Interviews}

The purpose of the pre-interviews was to highlight teachers' perceptions and understanding of the integration of simulations and the relevant teaching strategies involved. The postinterviews aimed to reflect changes in teachers' perceptions and understanding of simulationbased instruction after receiving the training. Before introducing the intervention, the researcher interviewed ten teachers separately and asked the following question:

- What do you think about the role of simulations in enhancing students' reasoning and communication skills in science?

Upon analyzing the data pertaining to this question, the following categories were identified:

a) Beneficial

b) Concrete learning

c) Inquiry/Discovery learning

d) Using the Simulations as virtual laboratory: 1-Feasibility of difficult experiments

2-Safety measures

3-Processes inside the body

4-Cost effective

e) Research

f) Critical thinking

Nine out of ten interviewees agreed that simulations were useful in teaching science. A number of teachers reported that they used simulations because they were dealing with digital natives and that simulations allowed learners to apply science. Moreover, all ten interviewees impressively agreed that simulations allowed learners to experience concrete learning by allowing them to visualize the learned concepts/processes and apply them. One teacher further elaborated: 
"They are very efficient, many topics require students not to learn only theories, they need to discover for example when they learn about systems how can they observe the parts of the digestive systems and see the journey of the food in the digestive system."

However, Inquiry-based learning integrated with simulations was mentioned only by three interviewees. Therefore, it seemed that most interviewees failed to establish the link between simulations and Inquiry-based learning, and their connection to enhancing reasoning and communication skills. In addition, six out of ten interviewees affirmed the use of simulations for virtual laboratories. They agreed that simulations ameliorate the drawbacks of laboratory applications by being more feasible, safe, cost effective and model internal processes. These findings align with what the literature has emphasized regarding the significant role of simulations in being complementary to laboratory practices (Unlu \& Dokme, 2014; Harbali, 2018). One teacher reported:

"Also simulations they are something basic that should be implemented more in all science classes, some experiments are difficult to perform in reality, we may use simulations to get the concept. Also, we use virtual labs as simulations to get concepts, sometimes we have toxic substances we cannot add during chemistry sessions for chemical reactions so they can observe the signs of chemical reactions using simulations". (Interview)

In addition, only two teachers mentioned that simulations promoted reasoning and communication by tailoring for research through data collection and analysis. They also mentioned that simulations promoted critical thinking which included reasoning and communication. Therefore, a gap was evident among teachers in comprehending the proper use of simulations in reinforcing students' reasoning and communication skills.

After the researcher introduced the intervention training to the teachers, she interviewed them separately and asked the following question:

In your opinion, how well did the Inquiry-Model-Computer simulations help you in enhancing the reasoning and written communication skills of the students? (Interview)

Upon analyzing the data pertaining to this question, the following categories were identified:

a) Improved Fluency

b) Critical Thinking

c) Interaction and Reflection

Four interviewees mentioned that the intervention enhanced their students' critical thinking skills while communicating in writing. For instance, the science teacher in school D mentioned:

[...]the Inquiry-Model also enhanced the critical thinking process of my students and allowed them to express their thoughts by communicating them 
with their peers. This is because, when students analyzed and concluded, they had to express these thought verbally and in writing [...]. (Interview)

Other teachers elaborated that when students implemented critical thinking skills, they were involved in expressing their analysis of data, conclusions, and interpretations verbally and in writing. The integration of the latter critical thinking skills brought students to think, reflect on their thinking, interact with their peers, and project their thinking through written tasks such as drawing graphs, constructing tables, or writing descriptive texts. All ten interviewees confirmed that engaging students in group work, discovery learning, and written assignments reinforced their written communication skills. Such interactions in turn paved the way for students to reflect on what they thought which enhanced communication skills.

In conclusion, both pre-and post-interviews shared the common theme of Critical Thinking, however, the Improved Fluency and Interaction and Reflection emerged as new themes. The two emerging themes were due to the intervention part that required teachers to tackle students' written communication skills by working in groups and practicing active learning strategies in writing as in Think-Pair-Share, and $K W L H$ which brought students to practice metacognitive thinking, reflect on their ideas, and to consider alternative solutions to a given problem (BouJaoude, 2018).

\section{Results from Observations}

The purpose of the observation was to report instances of students' applying reasoning and/or communication skills when the teacher uses a simulation in the science class. A total of 22 observations were done in the pre-intervention phase in the five schools. Each grade level was observed once and therefore the total number of observations corresponded to the total number of sections per grade level.

It is worth noting however that, before introducing the intervention, scores were the highest on the reasoning level of "pick up information" ( $89 \%$ School D), "students ask questions" (79\% School D), "differentiate between causes and effects" (61\% School D), and the lowest on "analyzing" ( $0 \%$ in the five schools). As for written communication skills, the lowest scores were on the written communication item: "draw a table or graph" $(0 \%$ in the four experimental schools lower than $5 \%$ in the control school).

Contrary to the afore-mentioned points in the experimental schools was the control school. It integrated written communication through laboratory reports, drawing graphs and tables, and it approached simulations as a preparation for laboratory applications. Nevertheless, both experimental and control schools lacked a structured framework for integrating simulations, and proper instructional practices for enhancing students' reasoning and communication skills.

In conclusion, findings at the pre intervention level highlighted a slightly positive effect of integrating simulations on students' reasoning and communication skills, which appeared to be random and unstructured. However, pre-intervention observation results also revealed a 
need for integrating active learning strategies within a framework that implemented Inquiry instruction to enhance students' reasoning and communication. Such findings supported the rationale of this study.

After the researcher introduced the intervention to the participating teachers in the experimental schools, she conducted semi-structured post-observations. The purpose of those observations was to record changes in the instructional practices of the trained teachers in the classroom setting. The post-observations resulted in the emergence of the following themes:

\section{Successful Enhancement of "Analysis", "Interpretation" and "Conclusion"}

All four experimental schools were successful in implementing the Five-E instructional model-phases for the purpose of enhancing students' reasoning and communication skills. Additionally, all four schools were successful in enhancing students' reasoning skills in association with the integration of simulations in an Inquiry-Based-learning environment as compared to the pre-phase. However, it was well noted that the common reasoning skill tackled in the four schools was "Analysis", which was totally absent in the four schools at the time of pre-observations. Other tackled reasoning skills were "Interpretation" and "Conclusion". The highest percentage of observed reasoning skills was "Pick up Information" 27\% in School A, 33\% in School B, 34\% in School C, and 64\% in school D. The enhancement of reasoning skills was observed mostly when the teachers implemented the "Explain", "Elaborate", and "Evaluate" phases of the Five-E instructional model since they asked students to analyze relationships between variables observed on the simulation and make conclusions.

\section{Enhancement of Written Communication Except for "Drawing a Graph or Table"}

As for written communication skills, they were tackled during the "Engage" and "Explore" phases of the Five-E whereby students were asked to fill the KWLH charts, write laboratory reports, and work in groups which brought them to interact, retell summaries, and communicate them in writing. However, the percentage of the written communication skill of "Draw a table or a graph" remained constant at a mean percentage of $0 \%$. Subsequently, the intervention was effective in enhancing students' reasoning skills of analysis, interpretation, and conclusion as well as enhancing written communication in general, but was reluctant to enhance the written communication skills of drawing graphs or tables.

\section{Discussion}

The most interesting findings before introducing the intervention was that teachers' integration of simulations was fuzzy and random, they were unaware of their role when incorporating simulations, and they were not involving students in writing laboratory reports which were conducive to reinforcing reasoning and communication skills. Moreover, teachers were not teaching science using Inquiry-based computer simulation approaches, which implied that they were not trained to do so. The aforementioned findings matched what Harbali's (2018) study has reported about the unstructured integration of simulations in the 
Lebanese context and the need for teachers to incorporate inquiry-based instruction when using simulations. Furthermore, observation findings prior to the intervention highlighted that the reasoning subskills of "Analysis", "Interpretation" and "Conclusion" were addressed the least by the participating teachers while the written communication skills of "Drawing Graphs", and "Constructing Tables" had the lowest frequency of $0 \%$ before the intervention. Therefore, it was evident that tackling reasoning and written communication skills were not an integral part of the school's policy.

As for post-test findings, they indicated that students' performance in reasoning and written communication (at the level of writing a scientific text) significantly increased in comparison to pre-test scores, therefore implying that the intervention was effective. Therefore, these findings have aligned with the literature by confirming that teaching science through the lens of Social Constructivism by incorporating the Five-E instructional model enhances students' reflective thinking in science (Forman \& Pufall, 1988; Maida, 2011; Miranda, 2011). Nevertheless, although students' scores in written communication at the level of writing a descriptive scientific text increased, findings from observations highlighted that written communication skills at the levels of "Draw a Graph" and "Construct a Table" remained constant with a frequency of $0 \%$. This shed light on a significant gap among these schools in tackling the latter two communication skills. The latter failure could be attributed to the lack of mathematical competency among students in the skills of identifying variables and recognizing the relationship between the dependent and independent variables. Moreover, reasoning skills at the levels of "Analysis", "Interpretation" and "Conclusion" were addressed by teachers following the intervention and thus increased in frequency. This could be attributed to the hands-on practical component of the intervention that associated the phases of the Five-E to Bloom's Taxonomy and brought teachers to practice active learning strategies totackle students' reasoning skills while integrating simulations. Therefore, the intervention was successful in adhering to the TPACK theory by bringing teachers to implement the intersection level of the three knowledge elements (TK), (PK), and (CK) to reinforce students' reasoning skills. This is also attributed to the successful implementation of the theory of Information Processing by reducing the cognitive load of students and by promoting rehearsal strategies(Maintenance rehearsal and Elaborative Rehearsal)which aided students in acquiring the reasoning skills properly (Tangen \& Borders, 2017). Therefore, their simulation use was not done haphazardly anymore, and it was well structured to fit the requirements of the Five-E instructional model. Besides, the interviewed teachers maintained that the intervention raised their awareness of varied instructional strategies and active learning strategies that included using the KWLH chart, Think-Pair-Share, group work, and writing laboratory reports which helped them in reinforcing students' reasoning and communication skills.

\section{Conclusion and Suggestion}

The latter findings rang the bell for policymakers, curriculum developers, and teacher training institutes to realize the gap in adhering to Social Constructivism and TPACK theories in teachers' practices for Cycle-two science, and to incorporate these two theories (Bybee et al., 
2006; Nordin et al., 2013; Chai et al., 2010; Erdogan \& Sahin, 2010). In addition, teachers need to be well trained to teach through a Constructivist approach that adopts computer simulations in inquiry-based learning environments, and they need to be trained to infuse the technological pedagogical knowledge (TPK) into their subject content taught.

Moreover, based on the aforementioned results, and given the need for ICT integration following the outbreak of the COVID-19 pandemic, it is recommended that schools provide further professional training sessions on the importance and the means of promoting reasoning, written communication skills when using simulations by practicing more studentcentred approaches. Therefore, the role of teachers when using simulations in an Inquirybased learning environment needed to be more emphasized by teacher training programs and institutions in association with filling the gap in technological pedagogical knowledge (Chai et al., 2011; Sang et al., 2009). The aforementioned findings generated a significant number of implications for each of the policymakers, stakeholders, Education Software Designers, the school, and the classroom levels.

\section{Implications for Policy Makers}

The results of this study projected the need for the Lebanese National Center for Educational Research and Development (NCERD) to initiate an education reform act that adopts reasoning and communication as essential requirements in the Cycle-two curriculum and associates them to the corresponding simulations after being customized to fit the Five-E instructional model.

\section{Implications for Stakeholders}

An important implication for stakeholders is to publish science books and curricula which specify learning objectives based on Bloom's Taxonomy and which integrate the ComputerSimulation-Inquiry instruction, and more specifically, the Five-E instructional model as a guide for the proper use of simulations. In other words, the science curricula should be based on TPACK theory. Moreover, publishing houses need to work collaboratively with Software developers in assigning the most useful ICT tool for each Science theme taught and make it adhere to reasoning and communication skills in the context of an interdisciplinary framework. These new curricula need to facilitate the use of computer-simulations and make it clear to teachers through their guidebooks.

Another implication is for teachers' pre-service and in-service training institutions to acknowledge the need for training teachers on how to implement simulations to tackle students' reasoning and communication in an Inquiry-based learning framework. Training programs should be preceded by and based on the assessment of teachers' professional development needs, and should always confirm practices of classroom management when integrating ICT. These teacher training and professional development institutions need to acknowledge the size of the gap in teachers' knowledge of technology and knowledge of pedagogy in using technology, and train teachers through the lens of the TPACK theory and 
in the light of Social Constructivism. Subsequently, teachers need to be well trained on how and when to use the active learning strategies that would enhance their students' reasoning and communication skills and supplement them with adequate knowledge construction tools.

\section{Implications for Education Software Designers}

According to the results of this study, and since teachers have a gap in acknowledging their guiding role when integrating computer-simulations, and also due to the total absence of instructional practices to teach students how to "Draw a Graph", and "Construct a Table", software designers need to scaffold students' learning to tackle these skills. This can be done by including worksheets and additional practices and instructions which supply students with the step-by-step tasks to accomplish when drawing graphs or tables using Excel sheets.

\section{Implications at the Levels of Schools}

As for private schools that are highly equipped with ICT tools, the results of this study highlighted a need for school networking to take place among teachers, administrators, and principals to share their experiences and practices and to generate products that might serve as teacher-guidebooks.

\section{Conflict of Interest}

The authors of the article declare no conflict of interest.

\section{Funding}

This research study was not funded by any institution. The authors conducted the study at their own expenses.

\section{Availability of Data and Material}

The data that support the findings of this study are available from the corresponding author, upon reasonable request.

\section{References}

Anderson, L.W., \& Krathwohl (Eds.). (2001). A Taxonomy for Learning, Teaching, and Assessing: A Revision of Bloom's Taxonomy of Educational Objectives. New York:Longman Atkin, J. M. and Karplus, R. (1962). Discovery of invention? Science Teacher 29(5): 45-51.

Atkin, J. M., \& Karplus, R. (1962). Discovery or invention? The Science Teacher, 29(5), 45-51.

Becker, K., and Park, K. (2011). Effects of integrative approaches among science, echnology, engineering, and mathematics (STEM) subjects on students' learning: A preliminary. meta- analysis. Journal of STEM Education. 12(5, 6), 23-37.

Retrieved from https://www.jstem.org/jstem/index.php/JSTEM/article/view/1509 
Bloom, B. S., Englehart, M. D., Furst, E. J., Hill, W. H., \& Krathwohl, D. R. (1956). Taxonomy of Educational Objectives, Handbook I: The Cognitive Domain. New York: David McKay Co.

BouJaoude, S. (2018, February). Instructional strategies to promote critical thinking: The Eighth International Conference on Effective Teaching and Learning in Higher Education. AUB:Beirut.

BouJaoude, S. (2007). Twenty-first century educational skills for development in the Mediterranean: Quality and curriculum relevance (pp. 82-89). In Med. 2007: 2006 in the Euro-Mediterranean Space. Barcelona, Spain: European Institute of the Mediterranean (IEMed). https://www.iemed.org/anuari/2007/aarticles/aBouJaoude.pdf

Bybee, R.W. (2014). The BSCS 5E instructional model: Personal reflections and contemporary Implications. Science and Children, 51(8), 10-13.

Bybee, R.W. (2009). The BSCS 5 E Instructional Model and $21^{\text {st }}$ Century Skills. The National Academics Board on Science Education.

Retrieved from https://ogur.org/gac_zuz_lecu_1_boci.pdf

Bybee, R.W., Taylor, J.A., Gardner, A., Van Scotter, P., Powell, J.C., Westbrook, A., and Landes, N. (2006). The BSCS5E Instructional Model: Origins and Effectiveness. Colorado: BSCS.

Chai, C. S., Koh, J. H. L., \& Tsai, C.-C. (2010). Facilitating preservice teachers' development of technological, pedagogical, and content knowledge (TPACK). Educational Technology \&Society, 13 (4), 63-73.

Cohen, L., Manion, L., \& Morrison, K. (2018). Research Methods in Education. ( ${ }^{\text {th }}$ ed.). RoutledgeTaylor \& Francis Group.

Creswell, J.W. (2014). Research Design. Croydon: Sage.

Dagher, Z. R., \& BouJaoude, S. (2011). Science education in Arab states: Bright future or status quo? Studies in Science Education, 47(1), 73-101. https://doi.org/10.1080/03057267.2011.549622

Dalgarno, B., Kennedy, G., \& Bennett, S. (2014). The impact of students' exploration strategies on discovery learning using computer-based simulations. Educational Media International, 51(4), 310-329.https://doi.org/10.1080/09523987.2014.977009

Dewey, J. (1971). How We Think. Chicago, Henry Regnery Company. Originally published In 1910.

Dickes, A.C., Kamarainen, A., Metcalf, S.J., Gun-Yildiz, S., Brennan, K., Grotzer, T., \& Dede, C. (2019). Scaffolding ecosystems science practice by blending immersive environments and computational modelling. British Journal of Educational Technology, 50 (5), 2181-2202. https://doi.org/10.1111/bjet.12806

Dong, C., Cao, S., \& Li, H. (2020). Young children's online learning during COVID-19 pandemic: Chinese parents' beliefs and attitudes. Children and Youth Services Review, 118, 1-9. doi: $10.1016 /$ j.childyouth.2020.105440

Duran, J.M. (2018). Computer Simulations in Science and Engineering: Concepts-practicesPerspectives. Springer. 
Efe, H.A. (2015). The relation between science student teachers' educational use of Web 2.0 technologies and their computer self-efficacy. Journal of Baltic Science Education. 14(1). 142-154.

Erdogan, A, \& Sahin, I. (2010). Relationship between math teacher candidates' technological pedagogical and content knowledge (TPACK) and achievement levels. Procedia-ocial and Behavioral Sciences, 2, 2707-2711. https://doi.org/10.1016/j.sbspro.2010.03.400

Fauzi, I., \& Khusuma, I.H.S. (2020). Teachers' elementary school in online learning of COVID-19 pandemic conditions. Jurnal Iqra: Kajian Ilmu Pendidikan, 5(1), 58-70. https://doi.org/10.25217/ji.v5i1.914

Forman, G., and Pufall, P.B. (1988). Constructivism in the Computer Age. Psychology Press, Taylor and Francis Group: New York, London.

Foy, P., Martin, M.O., Mullis, I.V.S, Yin, L., Centurino, V.A.S., \& Reynolds, K.A. (2015). Reviewing the TIMSS 2015 achievement item statistics. Methods and Procedures in TIMSS 2015 (pp. 1-43). IEA. Retrieved from https://isc.bc.edu/publications/timss/2015methods/T15_MP_Chap11_Reviewing_Achievement.pdf

Greenspan, Y.F. (2016). A Guide to Teaching Elementary Science: Ten easy steps. Springer. Halawi, L.A., McCarthy, R., \& Pires, S. (2009). An evaluation of e-learning on the basis of Bloom's taxonomy: an exploratory study. Journal of Education for Business, 84(6), 374-380. www.tandfonline.com

Harbali, A.B. (2018). The impact of inquiry-based virtual labs on $11^{\text {th }}$ grade students' achievement, inquiry skills and engagement case of teaching genetic engineering in Lebanese schools. [Unpublished doctoral dissertation]. Lebanese University.

Hardy, I., Kloetzer, B., Moeller, K., and Sodian, B. (2010). The analysis of classroom discourse: Elementary school science curricula advancing reasoning with evidence. EducationalAssessment, 15, 197-221.https://doi.org/10.1080/10627197.2010.530556

Hennessy, S., Deaney, R., \& Ruthven, K. (2006). Situated expertise in integrating use of multimedia simulation into secondary science teaching. International Journal of Science Education, 28(7), 701-732.

Hsu, T.Y., Kuo, F.R., Liang, H.Y., and Lee, M.F. (2016). A curriculum-based virtual and physical mobile learning model for elementary schools in museums. The Electronic Library. 34(6), 997-1012. https://doi.org/10.1108/EL-08-2015-0146

Hughes, C. (2014). Theory of knowledge aims, objectives, and assessment Criteria: An analysis of critical thinking descriptors. Journal of Research in International Education. 13(1), 30- 45. https://doi.org/10.1177/1475240914528084

Karplus, R., \& Thier, H. D. (1967). A New Look at Elementary School Science, New Trends In Curriculum and Instruction Series. Rand McNally.

Kriz, W.C. (2020). Gaming in the time of COVID-19. Simulations \& Gaming, 51(4), 403410. https://doi.org/10.1177/1046878120931602

Krathwohl, D.R. (2002). A revision of Bloom's Taxonomy: An overview. Theory into Practice, 41(4), 212-222.

Lee, A. T., Hairston, R. V., Thames, R., Lawrence, T., Herron, S. S. (2002). Using a Computer Simulation to teach science process skills to college biology and elementary majors. Bioscene, 28(4), 35-42. Retrieved from https://aquila.usm.edu/fac_pubs/14849 
Lye, S.-Y., Wee, L.-K., Kwek, Y.-C., Abas, S., \& Tay, L.-Y. (2014). Design, customization and implementation of energy simulation with 5E Model in Elementary Classroom.

Educational Technology \& Society, 17 (3), 121-137.Retrieved from https://about.jstor.org/terms

Maida, C.A. (2011). Project-based learning: A critical pedagogy for Twenty-First Century. Policy Futures in Education, 9(6), 759-768. Retrieved from www.wwwords.co.uk/PFIE

Miranda, J. (2011). Constructivism in the non-traditional system of education. Phillippiniana Sacra, 116(137), 313-344.

Mishra, P., \& Koehler, M. J. (2006). Technological pedagogical content knowledge: A framework for teacher knowledge. Teachers college record, 108(6), 1017-1054.

National Center for Educational Research and Development (NCERD). (1999). Evaluation Guide de L'Enseignant Sciences Generales [Evaluation Guide of Students in General Sciences]. Lebanon: NCERD.

Nordin, H., Davis, N., Tengku Ariffin, T.F. (2013). A case study of pre-service secondary teachers' technological pedagogical and content knowledge mastery level. ProcediaSocial and Behavioral Sciences, 103, 1-.https://doi.org/10.1016/j.sbspro.2013.10.300

OECD. (2009). PISA 2009 Assessment Framework, Key Competencies in Reading, Mathematics, And Science. Paris: OECD. Retrieved from http://www.oecd.org

OECD. (2013). PISA 2015 Draft Science Framework. Paris:

OECD.https://www.oecd.org/pisa/pisaproducts/Draft\%20PISA\%202015\%20Science\% 20Framework\%20.pdf

Pedaste, M., Mäeots, M., Siiman, L. A., De Jong, T., Van Riesen, S. A., Kamp, E. T., ... \& Tsourlidaki, E. (2015). Phases of inquiry-based learning: Definitions and the inquiry cycle. Educational research review, 14, 47-61.

Sang, G., Valcke, M., Braak, J.V., \& Tondeur, J. (2009). Student Teachers' Thinking Processes and ICT Integration: Predictors of Prospective Teaching Behaviors with Educational Technology. Computers and Education, 1-10. doi:

0.1016/j.compedu.2009.07.010

Schunk, D.H. (2016). Learning theories: An educational perspective ( $7^{\text {th }}$ ed.). Boston, MA: Pearson.

Shope, R.E., and McComas, W.F. (2015). Modeling Scientific Inquiry to Guide Students in the Practices of Science: The ED3U Teaching Model of Conceptual Change in Action, Innovations in Higher Education Teaching and Learning. 4, 217-240. https://doi.org/10.1108/S2055-364120150000004013

Shulman, L. S. (1986). Those who understand: Knowledge growth in teaching. Educational researcher, 15(2), 4-14.

Singh, M.K., Singh, S., Kumari, A., and Kumar, P. (2011). Teach biology science using a computer simulation process. International Transactions in Applied Sciences. 4(2),267270.

Smetana, L.K., \& Bell, R.L. (2012) Computer simulations to support science instruction and learning: A critical review of the literature. International Journal of Science Education,34(9), 1337-1370. DOI: 10.1080/09500693.2011.605182. 
Tangen, J.L., \& Borders, L.D. (2017). Applying information processing theory to supervision: An Initial exploration. Counselor Education and Supervision, 56, 98-111.

Tsai, F.H. (2017). The Development and Evaluation of a Computer-Simulated Science Inquiry Environment Using Gamified Elements. Journal of Educational Computing Research. 0(0), 1-20.https://doi.org/10.1177/0735633117705646

Unlu, Z.K., \& Dokme, I. (2014). Seventh grade students' views on combining the use of computer simulations and laboratory activities in science teaching. Social and Behavioral Sciences, 191,1173-1177. doi: 10.1016/j.sbspro.2015.04.258.

Williamson, K.C., \& Anderson, A.J. (2019). Reasoning ability as a predictor of success in a construction surveying course. International Journal of Construction Education and Research, 15(1), 42-61. https://doi.org/10.1080/15578771.2017.1380733

Wu, H.L., Weng, H.L, and She, H.C. (2016). Effects of scaffolds and scientific reasoning ability on web-based scientific inquiry. International Journal of Contemporary Educational Research, 3(1), 12-24. Retrieved from www.ijcer.net

Yehya, F.M. (2018). Impact of computer simulation on students' cognitive achievement in Physics courses. (Unpublished doctoral dissertation), Saint-Joseph University, Beirut.

Zeitoun, S., \& Hajo, Z. (2015). Investigating the science process skills in cycle 3 national science textbooks in Lebanon. American Journal of Educational Research, 3(3), 268275. https://doi.org/10.12691/education-3-3-3 